\title{
Pyrethroid resistance in Anopheles gambiae leads to increased susceptibility to the entomopathogenic fungi Metarhizium anisopliae and Beauveria bassiana
}

\author{
Annabel FV Howard*1 ${ }^{* 1}$ Constantianus JM Koenraadt ${ }^{1}$, Marit Farenhorst ${ }^{1}$, Bart GJ Knols² and Willem Takken¹
}

\begin{abstract}
Background: Entomopathogenic fungi are being investigated as a new mosquito control tool because insecticide resistance is preventing successful mosquito control in many countries, and new methods are required that can target insecticide-resistant malaria vectors. Although laboratory studies have previously examined the effects of entomopathogenic fungi against adult mosquitoes, most application methods used cannot be readily deployed in the field. Because the fungi are biological organisms it is important to test potential field application methods that will not adversely affect them. The two objectives of this study were to investigate any differences in fungal susceptibility between an insecticide-resistant and insecticide-susceptible strain of Anopheles gambiae sensu stricto, and to test a potential field application method with respect to the viability and virulence of two fungal species

Methods: Pieces of white polyester netting were dipped in Metarhizium anisopliae ICIPE-30 or Beauveria bassiana IMI391510 mineral oil suspensions. These were kept at $27 \pm 1^{\circ} \mathrm{C}, 80 \pm 10 \% \mathrm{RH}$ and the viability of the fungal conidia was recorded at different time points. Tube bioassays were used to infect insecticide-resistant (VKPER) and insecticidesusceptible (SKK) strains of An. gambiae s.s., and survival analysis was used to determine effects of mosquito strain, fungus species or time since fungal treatment of the net.

Results: The resistant VKPER strain was significantly more susceptible to fungal infection than the insecticidesusceptible SKK strain. Furthermore, B. bassiana was significantly more virulent than $M$. anisopliae for both mosquito strains, although this may be linked to the different viabilities of these fungal species. The viability of both fungal species decreased significantly one day after application onto polyester netting when compared to the viability of conidia remaining in suspension.

Conclusions: The insecticide-resistant mosquito strain was susceptible to both species of fungus indicating that entomopathogenic fungi can be used in resistance management and integrated vector management programmes to target insecticide-resistant mosquitoes. Although fungal viability significantly decreased when applied to the netting, the effectiveness of the fungal treatment at killing mosquitoes did not significantly deteriorate. Field trials over a longer trial period need to be carried out to verify whether polyester netting is a good candidate for operational use, and to see if wild insecticide-resistant mosquitoes are as susceptible to fungal infection as the VKPER strain.
\end{abstract}

\section{Background}

It is estimated that in 2008 there were 243 million cases of malaria and 863,000 deaths [1]. Clearly, mosquito-borne diseases are still a major health risk, particularly in devel-

* Correspondence: afv.howard@gmail.com

1 Laboratory of Entomology, Wageningen University and Research Centre, P.O. Box 8031, 6700 EH Wageningen, The Netherlands

Full list of author information is available at the end of the article oping countries. Current mosquito control strategies depend heavily on insecticides but mosquito populations in various disease-endemic countries are developing resistance [2]. Because pyrethroids are the only insecticide class that has WHOPES approval for use on insecticide-treated nets, pyrethroid resistance can seriously hamper vector control activities. Not only does insecti- 
cide resistance reduce the capacity to repel and kill mosquitoes, there is also evidence that insecticides can select for certain behaviourally resistant traits, such as earlier mosquito feeding times and earlier exiting from houses with treated nets $[3,4]$. Furthermore, resistance to some insecticides can confer cross-resistance to other insecticides, notably the organochlorine DDT [5-8]. There is, therefore, an urgent need for alternative tools or strategies that can effectively control insecticide-resistant mosquito populations.

At present biocontrol and biopesticide agents are only operational against mosquito larvae and pupae [9-12]. However, it is the longevity of the adult mosquito that has the greatest impact on the vectorial capacity, and hence transmission intensity, of a mosquito population [13]. Biocontrol agents that target the adult mosquitoes, and to which resistance cannot readily develop, would be useful tools for mosquito control.

The hyphomycetous entomopathogenic fungi Metarhizium anisopliae and Beauveria bassiana have been used to target pest insects for over a century [14], and have recently been evaluated for mosquito control purposes (see Table 1). These fungi infect mosquitoes through direct contact with the cuticle. The fungal conidia penetrate the mosquito cuticle and grow into the haemocoel where they produce a blend of organic compounds, causing internal mechanical damage, nutrient depletion and death [15]. Lethal effects start to occur three to four days after infection [16-19]. These entomopathogenic fungi are effective at killing both insecticide resistant and insecticide susceptible mosquito populations $[20,21]$. Furthermore, M. anisopliae and B. bassiana kill mosquitoes in a slower manner than insecticides kill insecticidesusceptible mosquito populations $[17,18,22,23]$. To prevent the evolution of resistance it is important to let organisms reproduce before they are killed to allow more than just the individuals with resistance/tolerance genes to contribute to the next generation. It is therefore thought that resistance to fungi will not evolve readily and that they have the possibility to be "evolution-proof" $[24,25]$. This late acting approach is possible in malaria control where the extrinsic incubation period (EIP) of the parasite is usually three to four gonotrophic cycle lengths (depending on temperature and female susceptibility to infection with Plasmodium). Ideally the fungi would kill the mosquito after reproduction had occurred but before she can transmit the malaria parasite.

Previous studies have used many different combinations of formulation/substrate (Table 1) to demonstrate the effectiveness of entomopathogenic fungi to infect and kill mosquitoes. However, many of the application methods previously used cannot be deployed easily in the field, either for small-scale tests or for operational vector con- trol. Because fungal spores are biological entities that are affected by the application (formulation/substrate) methods used, it is important to test potential methods that can be used in the field. Many traditional rural African houses are built with open eaves to help air flow within the house. Trials in The Gambia and São Tomé have shown that eaves are important house entry points for Anopheles gambiae s.l. [26,27]. Rural African houses also tend to have open windows through which mosquitoes can enter. Eave curtains and insecticide-treated curtains have proven effective at decreasing the numbers of indoor-resting mosquitoes [28] and reducing child mortality [29]. Curtains have a smaller surface area than bed nets, do not come into close contact with humans and would be hung where mosquitoes enter houses. Application of fungal spores onto curtains may, therefore, be a potential application method for mosquito control in the field.

There were two objective of this study, the first was to compare the fungal-susceptibility of an insecticide-resistant and insecticide-susceptible strain of Anopheles gambiae s.s.. The second objective was to test a potential application method that could be used in the field. Therefore, M. anisopliae and B. bassiana conidia were suspended in mineral oil and these suspensions were separately applied onto white polyester netting. The potential of these treated nets to infect and kill An. gambiae s.s. SKK (an insecticide-susceptible strain) and $A n$. gambiae s.s. VKPER (an insecticide-resistant strain) mosquitoes at different time points after the nets had been treated with fungal conidia was tested using tube bioassays. In addition, fungal viability after application onto the polyester nets was measured.

\section{Methods \\ Mosquitoes}

The two mosquito strains used in the bioassays were $A n$. gambiae s.s. VKPER and An. gambiae s.s. SKK. The SKK strain is an insecticide-susceptible strain originating from Suakoko, Liberia and maintained as a laboratory colony at Wageningen University, The Netherlands, since 1989. The VKPER strain is a pyrethroid-resistant strain that was initially collected from the Kou Valley, Burkina Faso and then selected repeatedly to fix the pyrethroid knockdown resistance $(k d r)$ gene. This gene causes target site insensitivity [5] and was first reported in West African mosquitoes in the early 1990s [30]. The VKPER strain has been maintained as a colony at the Centre de Recherché Entomologique de Cotonou (CREC) in Benin, West Africa, for several years. Eggs from this colony were shipped to Wageningen University, The Netherlands, and a colony was started. 
Table 1: Different formulation/substrate application methods used to infect adult malaria vector mosquitoes in previous studies.

\begin{tabular}{|c|c|c|c|c|c|}
\hline Fungus & Formulation & Substrate & Mosquito species & Lab or field & Ref. \\
\hline B. bassiana & Dry conidia & & An. albimanus & Laboratory & {$[42]$} \\
\hline B. bassiana & Dry conidia & Agar plate & An. gambiae s.s. & Laboratory & [17] \\
\hline B. bassiana & Dry conidia & Plastic tube & $\begin{array}{l}\text { An. gambiae s.S.; An. } \\
\text { funestus; } A n . \\
\text { arabiensis }\end{array}$ & Laboratory & {$[20,21]$} \\
\hline B. bassiana & Dry conidia & Tissue paper & An. gambiae s.l. & Laboratory & [19] \\
\hline B. bassiana & Ondina oil & Cardboard & An. gambiae s.s. & Laboratory & [31] \\
\hline B. bassiana & Ondina oil & Paper and netting & An. gambiae s.s. & Laboratory & {$[43]$} \\
\hline B. bassiana & Ondina oil/ShellSol T & Cage mesh & An. stephensi & Laboratory & {$[36,37]$} \\
\hline B. bassiana & Ondina oil/ShellSol T & Cardboard pot & An. stephensi & Laboratory & {$[36]$} \\
\hline B. bassiana & Ondina oil/ShellSol T & Direct application & An. stephensi & Laboratory & {$[36]$} \\
\hline B. bassiana & ShellSol T & Cardboard & An. gambiae s.s. & Laboratory & {$[31]$} \\
\hline B. bassiana & ShellSol T & Proofing paper & An. gambiae s.s. & Laboratory & [31] \\
\hline M. anisopliae & Coconut oil & Filter paper & An. stephensi & Laboratory & {$[22]$} \\
\hline M. anisopliae & Dry conidia & & An. stephensi & Laboratory & {$[22]$} \\
\hline M. anisopliae & Dry conidia & Agar plate & An. gambiae s.s. & Laboratory & [17] \\
\hline M. anisopliae & Dry conidia & Plastic tube & An. gambiae s.s. & Laboratory & {$[16]$} \\
\hline M. anisopliae & Enerpar oil & Proofing paper & $\begin{array}{l}\text { An. gambiae s.s.; An. } \\
\text { arabiensis }\end{array}$ & Laboratory & {$[23]$} \\
\hline M. anisopliae & Enerpar/Ondina oil & Black cotton cloth & An. arabiensis & Field & {$[40]$} \\
\hline M. anisopliae & Ondina oil & Paper and netting & An. gambiae s.s. & Laboratory & {$[43]$} \\
\hline M. anisopliae & Ondina oil & Cardboard & An. gambiae s.s. & Laboratory & {$[31]$} \\
\hline M. anisopliae & Ondina oil & Clay pot & $\begin{array}{l}\text { An. gambiae s.s.; An. } \\
\text { funestus }\end{array}$ & Laboratory & {$[18]$} \\
\hline M. anisopliae & Ondina oil/ShellSol T & Cage mesh & An. stephensi & Laboratory & [37] \\
\hline M. anisopliae & Ondina oil/ShellSol T & Cardboard pot & An. stephensi & Laboratory & {$[36]$} \\
\hline
\end{tabular}


Table 1: Different formulation/substrate application methods used to infect adult malaria vector mosquitoes in previous studies.

\begin{tabular}{llllll}
\hline M. anisopliae & ShellSol T & Cardboard & An.gambiae s.s. & Laboratory & [31] \\
\hline M. anisopliae & ShellSol T & Proofing paper & An.gambiae s.s. & Laboratory & [31] \\
\hline M. anisopliae & Sunflower oil & Cotton netting & An.gambiae s.s. & Laboratory & [38] \\
\hline M. anisopliae & Sunflower oil & Filter paper & An.gambiae s.s. & Laboratory & [16,44] \\
\hline M. anisopliae & Vegetable oil & Black cotton sheets & An.gambiae s.l. & Field & [39] \\
\hline M. anisopliae & Vegetable oil & Mud wall & An.gambiae s.s. & Field & [38]
\end{tabular}

Only studies using B. bassiana and/or M. anisopliae were included in this table

Both mosquito strains were subject to standard rearing procedures using tap water in plastic trays $(10 \times 25 \times 8$ $\mathrm{cm})$ and fed with Tetramin fish food daily. Pupae were selected daily and adults were held in standard $30 \times 30 \times$ $30 \mathrm{~cm}$ gauze-covered cages and fed on a $6 \%$ glucose solution ad libitum. The larval trays and adult cages were kept in climate chambers held at $27 \pm 1^{\circ} \mathrm{C}, 80 \pm 10 \% \mathrm{RH}$ and a $12 \mathrm{hr}$ L:D photoperiod.

\section{Fungi}

Two species of fungi were studied. Metarhizium anisopliae var. anisopliae, Sorokin isolate ICIPE-30, was produced at Wageningen University, The Netherlands, using solid-state fermentation in aerated packed bed systems with glucose impregnated hemp as a growth substrate. Beauveria bassiana Vuillemin IMI 391510 was produced in the laboratory of Penn State University, USA, by initially growing the fungus in a liquid medium and then inoculating autoclaved barley flakes in mushroom spawn bags.

Fungal conidia were dried at ambient temperature $(<5 \%$ $\mathrm{RH})$ and stored in the refrigerator until use. Dry conidia of $M$. anisopliae and $B$. bassiana were separately suspended in the synthetic isoparaffinic hydrocarbon solvent ShellSol T ${ }^{\mathrm{rm}}$ (Shell, The Netherlands). ShellSol T was selected because the delivery system of fungal conidia suspended in this solvent has been shown to be significantly more virulent to $A n$. gambiae s.s. mosquitoes when compared to conidia suspended in other oils [31]. A Bürker-Türk haemocyte counter and light microscope (at $\times 400$ ) were used to determine accurate conidial concentrations per $\mathrm{ml}$ ShellSol T. Fresh suspensions were made for each experimental replicate.

\section{Net treatment}

The netting used was made of white $100 \%$ multifilament 150 denier warp-knitted polyester fibres with a mesh size of 12 holes $/ \mathrm{cm}^{2}$ (Vestergaard Frandsen, Switzerland).
Pieces $15 \times 25 \mathrm{~cm}$ were used and dipped in the conidia/ ShellSol T suspensions resulting in treatment densities of $7.2 \times 10^{12}$ conidia per $\mathrm{m}^{2}$. Control netting was treated with ShellSol T only.

Fungus-treated pieces of netting were held in a climate chamber at Wageningen University under constant conditions of $27 \pm 1^{\circ} \mathrm{C}, 65 \pm 10 \% \mathrm{RH}$, to simulate average climatic conditions of field settings. The viability of fungal conidia (see below) was scored at 1 and 7 days post-treatment, and mosquito bioassays (see below) were run 2 and 7 days post-treatment.

\section{Tube bioassays}

Separate pieces of control, M. anisopliae or B. bassianatreated netting were placed into a tube bioassay set up $(8$ $\mathrm{cm}$ diameter $\times 15 \mathrm{~cm}$ high; see Figure 1E in Farenhorst and Knols [31]) such that the netting covered the inside of the tube. These were stored in a climate chamber at Wageningen University at $27 \pm 1^{\circ} \mathrm{C}, 65 \pm 10 \% \mathrm{RH}$ until testing. Tests were carried out in the climate chamber on day 2 and 7 after net treatment.

For the bioassays, the tubes were sealed at both ends with cling film, a surface that mosquitoes do not like resting on. Twenty-five 3-5 day old non-blood fed female $A n$. gambiae VKPER or SKK strain mosquitoes were introduced into each tube and exposed to the nets for $1 \mathrm{hr}$. Four replicates were performed per time point. After the exposure time the mosquitoes were placed into cups and had access to $6 \%$ glucose solution ad libitum. Every $24 \mathrm{hrs}$ mosquitoes were recorded as being alive if they were still able to fly [32]. Mortality was scored until all the fungusexposed mosquitoes had died.

Dead mosquitoes were removed daily and checked for fungal infection. Cadavers were dipped in $70 \%$ ethanol, for external sterilization, and placed onto moist filter paper in Petri dishes that were then sealed with Parafilm and placed into a $27^{\circ} \mathrm{C}$ incubator in the dark. After three days it was possible to visually score the proportion of 

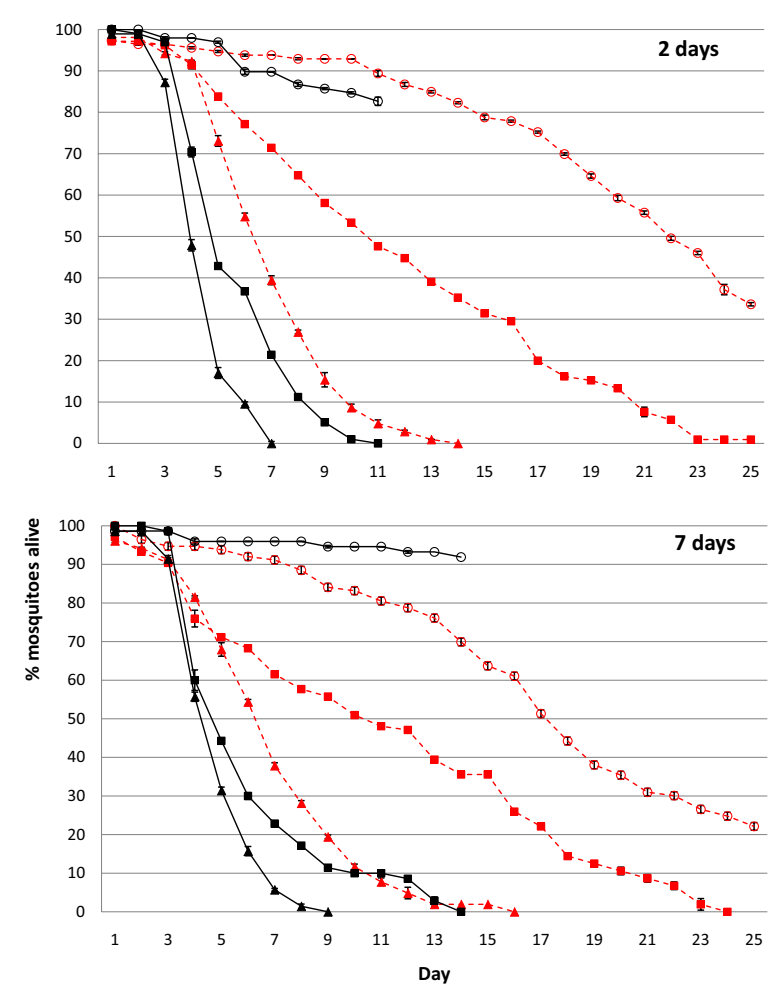

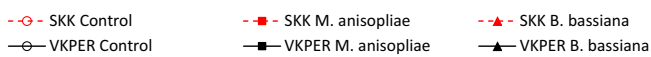

Figure 1 Effect of entomopathogenic fungal infection on Anopheles gambiae survival. Mean cumulative proportional survival ( \pm SEM) of Anopheles gambiae s.s. SKK (dashed red) and An. gambiae s.s. VKPER (solid black) mosquitoes after exposure to Metarhizium anisopliaetreated (filled squares), Beauveria bassiana-treated (filled triangles) or control (open circles) netting 2 (top) or 7 (bottom) days after net treatment.

mosquitoes showing fungal infection based on the presence of sporulating fungal hyphae (M. anisopliae conidia are green, $B$. bassiana conidia are white).

\section{Fungal viability}

As a measure for conidial viability, the germination of the conidia on a rich agar medium was counted. Either a drop of the conidial suspension or a $1 \mathrm{~cm}^{2}$ piece of the treated netting was placed onto Sabouraud Dextrose Agar (SDA) plates. The SDA plates had $0.001 \%$ benomyl added so that accurate germination could be recorded; benomyl is a fungicidal compound that restricts the hyphal growth without affecting germination [33]. These plates were then incubated at $27^{\circ} \mathrm{C}$ in the dark and germination was scored 24 hrs later using a light microscope at $\times 400$. A conidium was scored as germinated if the germ tube was at least twice the length of the conidium. A minimum of 300 conidia were counted per plate; four replicates of each fungus species/time point were carried out.

\section{Statistical analysis}

For the mosquito survival analysis, differences between the control and fungus-exposed mosquito survival rates were investigated using Cox Regression analysis in SPSS 17.0 [34]. Significant mosquito strain and fungus species effects were further investigated using Cox Regression. Mortality rates were given as Hazard Ratios (HR), which give the average daily risk of dying. Chi-square tests were carried out to investigate the difference between the fungal viability in suspension and on treated nets using SAS $9.1[35]$.

\section{Results}

\section{Tube bioassays}

Both M. anisopliae and B. bassiana were pathogenic to both strains of An. gambiae s.s., with significantly increased mortality in all fungus-exposed/mosquito strain combinations (Table 2). Survival curves for all fungus infected mosquitoes were significantly different from the respective controls both for the mosquitoes exposed two days post net treatment and those exposed seven days after net treatment (Figure 1). Furthermore, B. bassiana was significantly more pathogenic than $M$. anisopliae both for SKK (day $2 \mathrm{HR}=3.47, \mathrm{p}<0.0001$; day $7 \mathrm{HR}=$ 2.84, $\mathrm{p}<0.0001$ ) and VKPER (day $2 \mathrm{HR}=1.89, \mathrm{p}<0.0001$; day $7 \mathrm{HR}=1.45, \mathrm{p}<0.05$ ).

There was no significant difference between the control VKPER and control SKK mortalities $(\mathrm{HR}=1.63, \mathrm{p}=$ 0.053). However, the insecticide-resistant mosquito strain VKPER was significantly more susceptible to fungal infection when compared to the SKK strain after being exposed to both the two (M. anisopliae HR $=4.46, \mathrm{p}<$ $0.0001 ;$ B. bassiana $\mathrm{HR}=3.59, \mathrm{p}<0.0001$ ) and seven day old net treatments $(M$. anisopliae $\mathrm{HR}=2.54, \mathrm{p}<0.0001$; B. bassiana $\mathrm{HR}=2.33, \mathrm{p}<0.0001)$. The number of days since the fungal treatments were applied to the nets caused no significant differences in the mortality of either the SKK $(\mathrm{HR}=1.02, \mathrm{p}=0.85)$ or VKPER $(\mathrm{HR}=0.83, \mathrm{p}=$ $0.09)$ mosquitoes. This indicates that despite the significant drop in fungal viability, the efficacy of the fungal spores in terms of mosquito pathogenicity was equally high seven days after net application.

For both VKPER and SKK mosquitoes, $>80 \%$ of the dead mosquitoes that were exposed to the fungus-treated netting showed evidence of fungal infection in the form of sporulation. Sporulation rates by themselves do not equate to fungal infection because sporulation varies with many things including fungal dose and virulence of fungal isolate, age of the mosquito and presence of microbial competitors. Although not a perfect indicator for fungal infection, the sporulation of the M. anisopliae exposed mosquitoes could be of interest because the viability of the M. anisopliae used was so low. For the VKPER mos- 
Table 2: Survival analysis of two strains of Anopheles gambiae s.s. exposed to two species of entomopathogenic fungi.

\begin{tabular}{|c|c|c|c|c|c|}
\hline \multirow{3}{*}{$\begin{array}{c}\text { Fungus } \\
\text { M. anisopliae }\end{array}$} & \multirow{3}{*}{$\begin{array}{c}\text { Mosquito strain } \\
\text { SKK }\end{array}$} & \multicolumn{4}{|c|}{ Days after fungal treatment } \\
\hline & & \multicolumn{2}{|l|}{2} & \multicolumn{2}{|l|}{7} \\
\hline & & $3.18(2.31,4.37)$ & $<0.0001$ & $2.60(1.94,3.48)$ & $<0.0001$ \\
\hline & VKPER & $17.10(9.68,30.20)$ & $<0.0001$ & $29.94(12.72,70.46)$ & $<0.0001$ \\
\hline \multirow[t]{2}{*}{ B. bassiana } & SKK & $11.01(7.43,16.32)$ & $<0.0001$ & $7.38(5.21,10.45)$ & $<0.0001$ \\
\hline & VKPER & $32.25(17.63,59.02)$ & $<0.0001$ & $43.52(18.02,105.11)$ & $<0.0001$ \\
\hline
\end{tabular}

Data show Cox Regression Hazard Ratio outcomes $(95 \% \mathrm{Cl})$

Statistical $p$-values are relative to the relevant control

SKK $=$ the insecticide-susceptible An. gambiae s.s. SKK strain

VKPER $=$ the insecticide-resistant An. gambiae s.s. VKPER strain

quitoes that were exposed to the 2 day old $M$. anisopliae treated netting (which had a viability of $13 \%$ the day before the bioassay), $82 \%(80 / 98)$ of the mosquitoes showed fungal sporulation. For the mosquitoes exposed to the seven day old $M$. anisopliae net (where the viability was $2 \%), 84 \%$ (59/70) of the mosquitoes showed infection. This was not significantly different from the numbers infected on day $2\left(\mathrm{X}^{2}=0.02, \mathrm{df}=1, \mathrm{p}=0.65\right)$ despite the significant decrease in the viability of the spores on the netting.

\section{Fungal viability}

The viabilities, expressed as the germination rate of fungal conidia, of B. bassiana and M. anisopliae in the ShellSol $\mathrm{T}$ suspensions were $77 \%$ and $36 \%$ respectively. When the treated polyester net was kept in a climate chamber held at $27 \pm 1^{\circ} \mathrm{C}, 65 \pm 10 \% \mathrm{RH}$ for one day, the viabilities of B. bassiana and M. anisopliae were $71 \%$ and $13 \%$ respectively. These viabilities had both dropped significantly (B. bassiana $\chi^{2}=5.21$, d.f. $=1, \mathrm{p}<0.03 ; M$. anisopliae $\chi^{2}=192.9$, d.f. $=1, \mathrm{p}<0.0001$ ) when compared to the viabilities in suspension. The viabilities of the two fungal species after seven days in a climate chamber were $62 \%$ and $2 \%$ respectively, for $B$. bassiana and $M$. anisopliae. On top of the significant drop in viability one day after fungal spore application, seven days after net treatment there were significant losses in viability when compared to the day 1 viabilities for both fungal species (B. bassiana $\mathrm{X}^{2}=50.9$, d.f. $=1, \mathrm{p}<0.0001 ;$ M. anisopliae $\mathrm{X}^{2}$ $=215.5$, d.f. $=1, \mathrm{p}<0.0001)$.

\section{Discussion}

For both species of fungus tested, the insecticide-resistant An. gambiae s.s. VKPER strain was significantly more susceptible to fungal infection than the insecticidesusceptible An. gambiae s.s. SKK strain. The risk of dying was around 2-4 times higher for VKPER depending on fungal species and age of treatment on the net. A previous study used colony and wild F1 An. arabiensis mosquitoes that were exposed to dry conidia of $B$. bassiana. They found no significant differences between the fungal susceptibility of the insecticide-resistant or insecticidesusceptible strains [21]. Another study using dry conidia looked at various Anopheles species with various types of insecticide resistance and also found no differences in fungal susceptibility between the insecticide-susceptible and insecticide-resistant strains [20]. The main difference between this and previous studies is that in the present study, mosquitoes were exposed to ShellSol T formulated conidia for $1 \mathrm{hr}$, whereas the two studies mentioned above exposed mosquitoes to dry conidia for $24 \mathrm{hrs}$ $[20,21]$. Dry conidia have been shown to kill mosquitoes faster than oil formulated conidia [16]. It is therefore likely that the studies using the $24 \mathrm{hr}$ exposure to dry conidia, whilst good for proving any fundamental principles requiring high fungal infection, caused the mosquitoes to receive such high doses of fungal infection that any subtle strain effects could not be detected.

Beauveria bassiana was significantly more virulent than $M$. anisopliae for both mosquito strains. However, it is likely that the difference in virulence is linked to the differing viabilities of the B. bassiana and $M$. anisopliae on the treated nets used in this study as this would lead to lower doses being received by the $M$. anisopliae-exposed mosquitoes when compared to the mosquitoes exposed to B. bassiana. It is possible that batches of $M$. anisopliae with a higher viability would have similar results to $B$. bassiana because most other studies involving adult mosquitoes that have used these two fungal species have found no differences in their virulence. Blanford et al [36] tested a range of oil-formulated fungal isolates of $B$. bassi- 
ana and M. anisopliae against An. stephensi mosquitoes. One $M$. anisopliae isolate used did not prove virulent to mosquitoes, whilst the other had the same virulence as the $B$. bassiana isolates [36]. Similarly, a study examining different application methods found similar virulence levels for oil-formulated $M$. anisopliae and B. bassiana when applied to both proofing paper and cardboard, and when different doses of each fungus were applied to proofing paper [31]. When dry conidia were used, Scholte et al [17] found that $M$. anisopliae was significantly more virulent to mosquitoes than $B$. bassiana after a three day exposure, although it is unclear what the respective viabilities of the conidia were. Another study using dry conidia found that the virulence of $M$. anisopliae and $B$. bassiana were similar for a range of mosquito species and strains [20].

Broadly speaking, previous fungal studies in the laboratory have used application methods that fall into three categories; dry conidia, using paper as a substrate and using substrates that can directly be used in the field. Of the latter type, studies have been carried out using mosquito cage mesh [36,37], clay pots [18] and cotton netting [38]. In addition to these laboratory studies, field studies in Tanzania have used black cotton cloths $[39,40]$ and direct application onto a mud wall [38]. Of these studies, the fungal viabilities after application onto the substrates were measured for the cotton netting in the laboratory [38] and the black cotton cloths used in the field [39]. In the laboratory, the cotton netting was kept in aluminium foil in the same climate chambers as used in this study, and the viabilities of $M$. anisopliae were $100 \%$ in suspension, $94 \%$ one day after net treatment and $82 \%$ one week after net treatment [38]. For the black cotton sheets used in Tanzania, the $M$. anisopliae viability decreased from $96 \%$ in suspension to $95 \%$ one day after sheet impregnation and $83 \%$ after a week [39]. Unfortunately, due to the different conidial viabilities, doses, exposure times and formulations used for this study and the cotton netting laboratory trial [38] it is not possible to directly compare the relative effect of each type of netting/fungus application method at killing mosquitoes in the laboratory.

When looking at the viability data it appears that the polyester netting/ShellSol $\mathrm{T}$ application method would not be a very suitable method for the delivery of viable entomopathogenic fungal spores for mosquito control. However, the virulence data examining the direct effect on mosquito mortality tells a different story. Regardless of time since the treatment of nets with fungi, both fungal species caused significantly increased mortality to both mosquito strains used. The viability of the $M$. anisopliae treated nets was just $2 \%$ seven days after net treatment. However, the effectiveness of the fungal treatment at killing mosquitoes did not significantly deteriorate during the length of the trial and high infectivity rates were observed. The differences between the viability and virulence results may be due to the differing abilities of the fungal conidia to germinate on mosquito cuticles and benomyl enriched agar. Whilst benomyl has been shown to not adversely affect the germination of $M$. anisopliae spores when compared to their germination in liquid medium [33], it would be no surprise that such a difference occurs because benomyl is a fungicide and insects are the natural hosts for these fungi.

It is thought that the slow kill speed of entomopathogenic fungi could lead to them being evolution-proof against resistance [25]. This is because any resistancerelated genes would be diluted by the genes of susceptible individuals passed onto the next generation before they have succumbed to the fungal infection [25]. For this to be an ethically acceptable strategy for malaria control, the fungi should kill the mosquitoes before the parasite has completed its EIP inside the mosquito. The EIP of malaria parasites can be calculated using the equation $[\mathrm{N}$ $($ days $)=111 /\left(\mathrm{T}-\mathrm{t}_{\min }\right)$ ] from Detinova [41] where $\mathrm{T}$ is the mean temperature and $t_{\min }$ is taken as $16^{\circ} \mathrm{C}$ [41]. In this study, the experiments were carried out at $27^{\circ} \mathrm{C}$; at this temperature the EIP would be 10 days. If entomopathogenic fungi are used on window curtains or bednets, thus targeting host seeking mosquitoes, then a valid assumption would be that a mosquito acquires both fungal and malaria infections at the same time. Given an EIP of 10 days at the experimental temperature, these results show that for the VKPER strain mosquitoes, all mosquitoes would have been killed by $B$. bassiana by this time, and $>90 \%$ by $M$. anisopliae. In other words, very few fungusinfected VKPER mosquitoes would have survived long enough to transmit malaria. For the less susceptible SKK strain, B. bassiana would have killed $90 \%$ and $M$. anisopliae just $50 \%$ of the mosquitoes by the time the mosquitoes became infectious with malaria. This slower speed of kill found with $M$. anisopliae infected SKK could allow more malaria transmission to occur, but it will also allow more mosquito reproduction, and thus less chance of resistance to fungal infection developing.

\section{Conclusions}

This study shows for the first time that insecticide-resistant An. gambiae s.s. VKPER are significantly more susceptible to both fungal species when compared to the insecticide-susceptible An. gambiae s.s. SKK. This indicates that entomopathogenic fungi could be used in resistance management and integrated vector management programmes to target insecticide-resistant mosquitoes. Field trials over a longer trial period need to be carried out to see if wild insecticide-resistant mosquitoes are as susceptible as the colony strain used in this trial.

This is the first published study to treat polyester netting with fungal spores. Although fungal viability signifi- 
cantly decreased when applied to polyester netting, the effectiveness of the fungal treatment at killing mosquitoes did not significantly deteriorate during the length of the trial. Following this laboratory trial, studies should be carried out to determine whether polyester netting would be an effective application method for entomopathogenic fungi in the field.

\section{Competing interests}

The authors declare that they have no competing interests.

\section{Authors' contributions}

AFVH designed and undertook the study, analysed part of the data and drafted the manuscript. CJMK analysed part of the data. MF aided in study design and data collection. BGJK supervised the study and aided in study design. WT supervised the study and aided the drafting of the manuscript. All authors read and approved the final manuscript.

\section{Acknowledgements}

We would like to thank Nina Jenkins (Penn State University, USA) and Arjen Rinzema (Wageningen University, The Netherlands) for providing the Beauveria bassiana and Metarhizium anisopliae respectively. Gabriella Bukovinzkine' Kiss and the Laboratory of Entomology insectary team are thanked for providing the An. gambiae s.s. SKK mosquitoes, and Raphael N'Guessan is thanked for providing the An. gambiae s.s. VKPER mosquitoes. Matt Thomas and Marcel Dicke are thanked for their comments on a previous version of this manuscript, as are two anonymous reviewers. This study was funded by the Adessium Foundation, The Netherlands, and a travel grant from the Royal Dutch Academy of Arts and Sciences (KNAW).

\section{Author Details}

'Laboratory of Entomology, Wageningen University and Research Centre, P.O Box 8031, 6700 EH Wageningen, The Netherlands and 2Div. Infectious Diseases, Tropical Medicine \& AIDS, Academic Medical Center, F4-217 Meibergdreef 9, 1105 AZ Amsterdam, The Netherlands

Received: 26 April 2010 Accepted: 16 June 2010

Published: 16 June 2010

\section{References}

1. World Health Organisation: World Malaria Report 2009. 2009.

2. Hemingway J, Ranson H: Insecticide resistance in insect vectors of human disease. Ann Rev Entomol 2000, 45:371-391.

3. Pates $\mathrm{H}$, Curtis C: Mosquito behavior and vector control. Ann Rev Entomol 2005, 50:53-70.

4. Mathenge EM, Gimnig JE, Kolczak MS, Ombok M, Irungu LW, Hawley WA Effect of permethrin-impregnated nets on exiting behaviour, blood feeding success and time of feeding of malaria mosquitoes (Diptera: Culicidae) in Western Kenya. J Med Entomol 2001, 38:531-536.

5. Enayati AA, Vatandoost $\mathrm{H}$, Ladonni $\mathrm{H}$, Townson $\mathrm{H}$, Hemingway J: Molecular evidence for a kdr-like pyrethroid resistance mechanism in the malaria vector mosquito Anopheles stephensi. Med Vet Entomol 2003, 17:138-144.

6. Brengues C, Hawkes NJ, Chandre F, McCarroll L, Duchon S, Guillet P, Manguin S, Morgan JC, Hemingway J: Pyrethroid and DDT crossresistance in Aedes aegypti is correlated with novel mutations on the voltage-gated sodium channel gene. Med Vet Entomol 2003, 17:87-94.

7. Chandre F, Darrier F, Manga L, Akogbeto M, Faye O, Mouchet J, Guillet P: Status of pyrethroid resistance in Anopheles gambiae sensu lato. Bull World Health Organ 1999, 77(3):230-234.

8. Brooke BD, Kloke G, Hunt RH, Koekemoer LL, Temu EA, Taylor ME, Small G, Hemingway J, Coetzee M: Bioassay and biochemical analyses of insecticide resistance in southern African Anopheles funestus (Diptera: Culicidae). Bull Entomol Res 2001, 91:265-272.

9. Kay BH, Nam VS, Tien TV, Yen NT, Phong TV, Diep VT, Ninh TU, Bektas A, Aaskov JG: Control of Aedes vectors of dengue in three provinces of Vietnam by use of Mesocyclops (copepoda) and community-based methods validated by entomologic, clinical and serological surveillance. Am J Trop Med Hyg 2002, 66:40-48.
10. Mittal PK: Biolarvicides in vector control: challenges and prospects. $J$ Vector Borne Dis 2003, 40:20-32.

11. Howard AFV, Zhou G, Omlin FX: Malaria mosquito control using edible fish in western Kenya: preliminary findings of a controlled study. $B M C$ Publ Health 2007, 7:199.

12. Howard AFV, Adongo EA, Hassanali A, Omlin FX, Wanjoya A, Zhou G, Vulule J: Laboratory evaluation of the aqueous extract of Azadirachta indica (neem) wood chippings on Anopheles gambiae s.s. (Diptera: Culicidae) mosquitoes. J Med Entomo/ 2009, 46(1):107-114.

13. MacDonald G: The epidemiology and control of malaria. Oxford, UK: Oxford University Press; 1957.

14. Lord JC: From Metchnikoff to Monsanto and beyond: The path of microbial control. J Invertebr Pathol 2005, 89:19-29.

15. Gillespie AT, Clayton N: The use of entomopathogenic fungi for pest control and the role of toxins in pathogenesis. Pestic Sci 1989, 27:203-215

16. Scholte EJ, Njiru BN, Smallegange RC, Takken W, Knols BGJ: Infection of adult malaria (Anopheles gambiae s.s.) and filariasis (Culex quinquefasciatus) vectors with the entomopathogenic fungus Metarhizium anisopliae. Malar J 2003, 2:29.

17. Scholte EJ, Takken W, Knols BGJ: Pathogenicity of five East African entomopathogenic fungi against adult Anopheles gambiae s.s mosquitoes (Diptera: Culicidae). Proceedings of the Section Experimental and Applied Entomology of the Netherlands Entomological Society (NEV) 2003, 14:25-29.

18. Farenhorst M, Farina D, Scholte EJ, Takken W, Hunt RH, Coetzee M, Knols $B G J:$ African water storage pots for the delivery of the entomopathogenic fungus Metarhizium anisopliae to the malaria vectors Anopheles gambiae s.s. and Anopheles funestus. Am J Trop Med Hyg 2008, 78(6):910-916.

19. Achonduh OA, Tondje PR: First report of pathogenicity of Beauveria bassiana RBL1034 to the malaria vector, Anopheles gambiae s.l. (Diptera: Culicidae) in Cameroon. Afr J Biotech 2008, 7(8):931-935.

20. Farenhorst M, Mouatcho JC, Kikankie CK, Brooke BD, Hunt RH, Thomas MB, Koekemoer LL, Knols BGJ, Coetzee M: Fungal infection counters insecticide resistance in African malaria mosquitoes. PNAS 2009, 106(41):17443-17447

21. Kikankie CK, Brooke BD, Knols BGJ, Koekemoer LL, Farenhorst M, Hunt RH, Thomas MB, Coetzee M: The infectivity of the entomopathogenic fungus Beauveria bassiana to insecticide-resistant and susceptible Anopheles arabiensis mosquitoes at two different temperatures. Malar J 2010, 9:71.

22. Kamala Kannan S, Murugan $\mathrm{K}$, Naresh Kumar A, Ramasubramanian N, Mathiyazhagan P: Adulticidal effect of fungal pathogen, Metarhizium anisopliae on malaria vector Anopheles stephensi (Diptera: Culicidae). Afr J Biotech 2008, 7(6):838-841.

23. Mnyone LL, Russell TL, Lyimo IN, Lwetoijera DW, Kirby MJ, Luz C: First report of Metarhizium anisopliae IP46 pathogenicity in adult Anopheles gambiae s.s. and An. arabiensis (Diptera: Culicidae). Parasit Vectors 2009, 2:59.

24. Thomas MB, Read AF: Can fungal biopesticides control malaria? Nat Rev Microbiol 2007, 5:377-383.

25. Read AF, Lynch PA, Thomas MB: How to make evolution-proof insecticides for malaria control. PLoS Biology 2009, 7(4):e1000058. doi: 1000010.1001371/journal.pbio.1000058.

26. Njie M, Dilger E, Lindsay SW, Kirby MJ: Importance of eaves to house entry by anopheline, but not culicine, mosquitoes. J Med Entomol 2009, 46(3):505-510.

27. Charlwood JD, Pinto J, Ferrara PR, Sousa CA, Ferreira C, Gil V, de Rosaria VE: Raised houses reduce mosquito bites. Malar $\lrcorner$ 2003, 2:45.

28. Majori G, Sabatinelli G, Coluzzi M: Efficacy of permethrin-impregnated curtains for malaria vector control. Med Vet Entomol 1987, 1:185-192.

29. Diallo DA, Cousens SN, Cuzin-Ouattara N, Nebie I, llboudo-Sanogo E, Esposito F: Child mortality in a West African population protected with insecticide-treated curtains for a period of up to 6 years. Bull World Health Organ 2004, 82(2):85-91.

30. Martinez-Torres D, Chandre F, Williamson MS, Darriet F, Berge JB, Devonshire AL, Guillet P, Pasteur N, Pauron D: Molecular characterization of pyrethroid knockdown resistance $(k d r)$ in the major malaria vector Anopheles gambiae s.s. Insect Mol Biol 1998, 7:179-184. 
31. Farenhorst M, Knols BGJ: A novel method for standardized application of fungal spore coatings for mosquito exposure bioassays. Malar J 2010, 9:27.

32. World Health Organisation: Procedures for Insecticide Resistance Monitoring in Malaria Vectors, Bio-Efficacy and Persistence of Insecticides on Treated Surfaces. 1998. WHO/CDS/CPC/MAL/98.12

33. Milner RJ, Huppatz RJ, Swaris SC: A new method for assessment of germination of Metarhizium conidia. J Invertebr Pathol 1991, 57(1):121-123.

34. SPSS Inc: SPSS for Windows. 17.0th edition. Chicago, IL, USA; 2008.

35. SAS Institute Inc: SAS 9.1.2 Qualification Tools User's Guide. 9.1 th edition. Cary, NC, USA; 2004.

36. Blanford S, Chan BHK, Jenkins N, Sim D, Turner RJ, Read AF, Thomas MB: Fungal pathogen reduces potential for malaria transmission. Science 2005, 308:1638-1641.

37. Blanford S, Read AF, Thomas MB: Thermal behavior of Anopheles stephensi in response to infection with malaria and fungal entomopathogens. Malar J 2009, 8:72.

38. Scholte EJ: The entomopathogenic fungus Metarhizium anisopliae for mosquito control. In PhD Wageningen: Wageningen University; 2004.

39. Scholte EJ, Ng'habi K, Kihonda J, Takken W, Paaijmans KP, Abdulla S, Killeen GF, Knols BGJ: An entomopathogenic fungus for control of adult African malaria mosquitoes. Science 2005, 308:1641-1642.

40. Lwetoijera DW, Sumaye RD, Madumla EP, Kavishe DR, Mnyone LL, Russell $T L$, Okumu FO: An extra-domiciliary method of delivering entomopathogenic fungus, Metarhizium anisopliae IP 46 for controlling adult populations of the malaria vector, Anopheles arabiensis. Parasit Vectors 2010, 3:18.

41. Detinova TS: Age-grouping methods in diptera of medical importance with special reference to some vectors of malaria. Edited by: Organisation WH. Geneva: World Health Organisation; 1962.

42. Clark TB, Kellen WR, Fukuda T, Lindegren JE: Field and laboratory studies on the pathogenicity of the fungus Beauveria bassiana to three genera of mosquitoes. J Invertebr Pathol 1968, 11:1-7.

43. Mnyone LL, Kirby MJ, Lwetoijera DW, Mpingwa MW, Knols BGJ, Takken W, Russell TL: Infection of the malaria mosquito, Anopheles gambiae, with two species of entomopathogenic fungi: effects of concentration, coformulation, exposure time and persistence. Malar J 2009, 8:309.

44. Scholte EJ, Knols BGJ, Takken W: Infection of the malaria mosquito Anopheles gambiae with the entomopathogenic fungus Metarhizium anisopliae reduces blood feedings and fecundity. J Invertebr Pathol 2006, 91(1):43-49.

doi: $10.1186 / 1475-2875-9-168$

Cite this article as: Howard et al., Pyrethroid resistance in Anopheles gambiae leads to increased susceptibility to the entomopathogenic fungi Metarhizium anisopliae and Beauveria bassiana Malaria Journal 2010, 9:168

\section{Submit your next manuscript to BioMed Centra} and take full advantage of:

- Convenient online submission

- Thorough peer review

- No space constraints or color figure charges

- Immediate publication on acceptance

- Inclusion in PubMed, CAS, Scopus and Google Scholar

- Research which is freely available for redistribution

Submit your manuscript at www.biomedcentral.com/submit 